\title{
The gastric mucosa in radiologically negative acute gastrointestinal bleeding
}

\author{
M. J. S. LANGMAN ${ }^{1}$, J. H. HANSKY ${ }^{2}$, R. A. B. DRURY, AND F. AVERY JONES \\ From the Departments of Gastroenterology and Histopathology, Central Middlesex Hospital, London
}

EDITORIAL SYNOPSIS This is a study of acid secretion and gastric mucosal histology in patients who had gastrointestinal bleeding. Patients with normal biopsies had high acid secretion and were believed to have acute or chronic duodenal ulcer; those with chronic gastritis and lower acid secretion suggested that the bleeding was due to acute gastric ulceration. The gastric mucosae of 22 additional patients with bleeding acute gastric ulcers removed surgically all showed chronic gastritis. In the main group of 30 patients studied there was no clear-cut histological difference between those patients taking aspirin and those who had not.

No firm diagnosis can be made in many patients admitted to hospital with acute upper gastrointestinal haemorrhage. At the Central Middlesex Hospital, in spite of a vigorous early diagnostic policy, 720 of a series of 2,526 cases proved to have negative radiographs, and in only about half of the 720 was a definite acute lesion seen on gastroscopy (Avery Jones and Gummer, 1960). When 142 of these cases without a definite diagnosis were followed up three to eight years later, an abnormality came to light in only 33 (Avery Jones, Read, and Stubbe, 1959).

It has been suggested that salicylates are a significant cause of acute upper gastrointestinal bleeding, both from acute gastric erosions and from chronic peptic ulceration (Alvarez and Summerskill, 1958), but it is noteworthy that in their series a very high proportion of patients having recently taken salicylates were in the radiologically negative and gastroscopy-negative group. It is likely that most of these cases in fact had acute gastric erosions or duodenal ulcers, and it is possible that the acute erosions would occur in a mucosa which was particularly sensitive to injury, as by salicylates. As further evidence for this view Allibone and Flint (1958) found no difference in the number of takers of salicylates in cases of bleeding chronic gastric and duodenal ulcers compared with controls but noticed a marked difference for cases of acute gastric erosion.

In the stomach chronic superficial or atrophic gastritis may well be the basis for such a susceptibility

'Present address: Department of Medicine, Guy's Hospital, London, S.E.1.

${ }^{2}$ Present address: Department of Medicine, Monash University, Melbourne, Australia. to injury, whereas in the duodenum acid hypersecretion could be the contributory factor.

To investigate this problem and to determine whether cases of radiologically negative bleeding fall clearly into two separate groups, one with gastritis and the other with high acid secretion, gastric biopsy and acid secretory studies were done in a series of such cases. The biopsy findings were examined to determine if there is more gastritis in the patients with a history of taking aspirin before bleeding; and some histological studies were made on acute gastric erosions removed operatively to see if the ulcers occurred in areas of gastritis.

\section{METHOD}

Gastric mucosal biopsies were performed on 30 patients admitted to hospital in emergency with a history of haematemesis or melaena. A barium meal examination was performed during the admission and was normal in all cases; most also had a gastroscopy which was normal except for three which showed an acute gastric erosion. Blind gastric biopsy was performed by the usual technique with the Wood tube during the relevant admission after obvious bleeding had ceased. In no case did biopsy appear to cause fresh haemorrhage.

The histological sections were examined without knowledge of the clinical findings, and each biopsy was classified into one of the following five groups. These are similar to the stages of chronic gastritis described by Joske, Finckh, and Wood (1955).

1 NORMAL The surface epithelium was smooth and regular, and the gastric glands long, straight, and 
closely packed. Inflammatory cells in the lamina propria were absent or scanty.

2 MILD CHRONIC SUPERFICIAL GASTRITIS Chronic inflammatory cells, mainly plasma cells and lymphocytes, were present as a localized band in the superficial part of the lamina propria between the gastric pits. The gastric glands were normally preserved.

3 MARKED CHRONIC SUPERFICIAL GASTRITIS Chronic inflammatory cells extended more deeply through the mucosa, separating the gastric glands. The glands were still of normal size and contained acid- and pepsin-secreting cells.

4 EARLY CHRONIC ATROPHIC GASTRITIS Chronic inflammatory cells were present throughout the whole thickness of the mucosa. The gastric glands were distorted and shortened; acid- and pepsinsecreting cells were decreased in number and mucoid cells more numerous.

5 MARKED CHRONIC ATROPHIC GASTRITIS There were many chronic inflammatory cells, often associated with lymphoid follicles. Gastric glands were short and irregular, mainly composed of mucoid cells. Some gastric glands were completely atrophic, others showed intestinal metaplasia.

The histological findings were then correlated with any recent history of taking an aspirin compound. It was regarded as significant if any aspirin compound had been taken in the three days before the onset of bleeding.

Augmented histamine tests (Kay, 1953) were performed on most of the patients; they were usually done 10 to 14 days after admission, but sometimes later. The technique of the test was broadly similar to that of Baron (1963).

The significance of the biopsy abnormalities in relation to histological changes which occurred in the mucosa around acute gastric ulcers was studied retrospectively. Histological sections of acute gastric ulcers which had been removed surgically in the years 1953-62 were examined for evidence of chronic superficial or atrophic gastritis in the surrounding mucosa.

\section{RESULTS AND DISCUSSION}

Thirty cases were investigated by gastric biopsy, and 24 of these had acid secretory studies performed. Acute gastric erosions were demonstrated gastroscopically in three of the patients, but in the remaining 27 cases no definite diagnosis could be made.

Table I shows the biopsies classified histologically
TABLE 1

BIOPSY HISTOLOGY IN RELATION TO HISTORY OF SALICYLATE INTAKE AND AGE OF PATIENTS

$\left.\begin{array}{lcccc}\text { Histology } & \begin{array}{l}\text { Salicylate } \\ \text { Positive }\end{array} & \begin{array}{c}\text { Salicylate } \\ \text { Negative }\end{array} & \text { Total } & \begin{array}{c}\text { Mean Agc } \\ \text { in Years }\end{array} \\ \hline \begin{array}{lccc}\text { Normal } \\ \begin{array}{l}\text { Mild chronic superficial } \\ \text { gastritis }\end{array}\end{array} & 6(1)^{1} & 3 & 9(1) & 51 \cdot 0 \\ \begin{array}{l}\text { Marked chronic superficial } \\ \text { gastritis }\end{array} & 2(1) & 2(1) & 4(2) \\ \begin{array}{l}\text { Early chronic atrophic } \\ \text { gastritis }\end{array} & 2(1) & 1(1) & 3(2) \\ \begin{array}{l}\text { Marked chronic atrophic } \\ \text { gastritis }\end{array} & \begin{array}{l}1(1) \\ 14\end{array} & \begin{array}{c}3(1) \\ 16\end{array} & \begin{array}{r}4(2) \\ 30\end{array}\end{array}\right\}$

'Figures in brackets denote numbers of women included in the figures above.

and in relation to the history of aspirin intake. It will be seen that less than a third of all the biopsies were completely normal, and in all three cases of acute gastric erosion a marked chronic atrophic gastritis was found on biopsy. One had taken aspirin and two had not. There are a few more normal biopsies in the aspirin-taking patients than in the remainder, but otherwise there is little difference in the histological changes between the two groups.

In the present series there is a striking uniformity of mean age between the various histological groups, yet previous gastric histological studies have suggested that chronic gastritis increases in degree and frequency with age (Coghill, 1960). An age limit of 70 was applied by us in this investigation, but this would seem too high to have affected the results. There are two ways in which these apparently different conclusions can be reconciled: either the abnormal biopsies came from a population with abnormal and prematurely aged gastric mucosae, which had a tendency to bleed, or the normal biopsies came from mucosae which had remained normal for unusually long, such as could perhaps happen in cases of duodenal ulceration.

Some evidence can be submitted to suggest that both of these factors could be important. Table II shows the amount of gastritic change noted at the sites of 22 acute gastric erosions removed because of haemorrhage. In all of the cases some degree of

\section{TABLE II}

HISTOLOGY AT THE SITES OF ACUTE GASTRIC ULCERS REMOVED SURGICALLY BECAUSE OF HAEMORRHAGE

Histology

No. of Cases

Normal

Mild chronic superficial gastritis

Marked chronic superficial gastritis

Early chronic atrophic gastritis

Marked chronic atrophic gastritis 
chronic gastritis was found. It is possible that changes resembling chronic superficial gastritis could develop around the sites of acute gastric ulcers after the mucosa has become eroded, but it seems improbable that atrophic gastritis could be produced within such a short time in such circumstances, yet half of the acute ulcers are surrounded by an atrophic mucosa. The most reasonable explanation of the results must be that chronic gastritis, especially when atrophic, renders the mucosa liable to acute erosion.

It might have been expected that if salicylates were important in the genesis of acute gastric erosions the biopsy material in the salicylate-positive cases would have shown more, rather than less, gastritis than in the salicylate-negative material. The groups are, however, rather small and so the evidence is not sufficient for any firm conclusion on this point.

The acid secretory studies (Table III) show that acid production decreases markedly as gastric histology becomes abnormal. The results here agree well with those of Bock, Richards, and Witts (1963). The cases with normal biopsies show a mean acid production in the stimulated hour of $29.3 \mathrm{mEq}$. This figure is the mean of only six observations, but it is in excellent agreement with the results from 18 male patients with radiologically proven duodenal ulceration who had suffered a recent haematemesis or melaena. These cases had a mean output of 29.5 mEq. in the stimulated hour (Langman, 1963, un-

\section{TABLE III}

ACID SECRETION IN RELATION TO GASTRIC HISTOLOGY IN THE BIOPSY SERIES

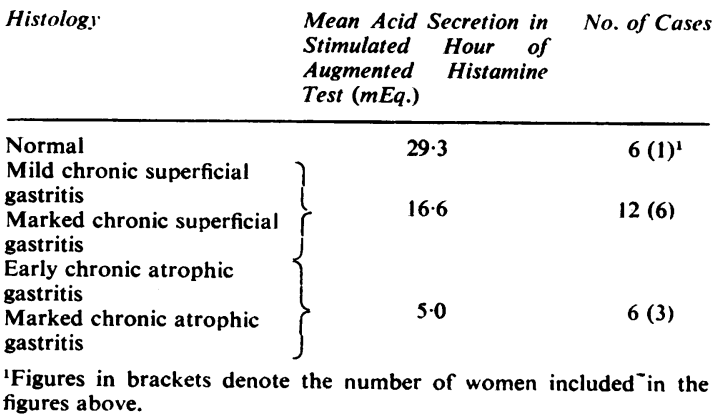

published data). In addition one further patient who had suffered a haematemesis, but had a normal barium meal and gastric biopsy, was shown to have a nocturnal gastric hypersecretory pattern which was typical of duodenal ulceration.

It is possible that a haemorrhage may reduce gastric acid secretion on testing shortly afterwards, as figures obtained in this laboratory in other cases of duodenal ulcer, which have not bled, reach a mean which is $6 \mathrm{mEq}$. higher. The suggestion that the radiologically negative cases with normal biopsies and comparatively high acid secretion have duodenal ulcers is reinforced by the follow-up study of Avery Jones et al. (1959) already mentioned. Seventeen of their 33 cases of radiologically negative bleeding which later reached a definite diagnosis proved to have a chronic duodenal ulcer.

From the present investigation it would seem that most cases of radiologically negative bleeding will fall into one of two groups. Those patients with abnormal gastric biopsies and low acid secretion probably have acute gastric ulcers, whilst those with normal biopsies and high acid secretion have duodenal ulcers. Gastric mucosal biopsy and studies of acid secretion may therefore determine the site of bleeding when other investigations are unhelpful, although the borderline between groups is not well defined.

\section{REFERENCES}

Allibone, A., and Flint, F. J. (1958). Gastrointestinal haemorrhage and salicylates. Lancet, 2, 1121.

Alvarez, A. S., and Summerskill, W. H. J. (1958). Gastrointestinal haemorrhage and salicylates. Ibid., 2, 920-925.

Baron, J. H. (1963). Studies of basal and peak acid output with an augmented histamine test. Gut, 4, 136-144.

Bock, O. A. A., Richards, W. C. D., and Witts, L. J. (1963). The relationship between acid secretion after augmented histamine stimulation and the histology of the gastric mucosa. Gut, 4. 112-114.

Coghill, N. F. (1960). The significance of gastritis. Postgrad. med. J., 36, 733-742.

Jones, F. Avery, and Gummer, J. W. P. (1960). Clinical Gastroenterology. Blackwell, Oxford.

_- Read, A. E., and Stubbe, J. L. (1959). Alimentary bleeding of obscure origin; a follow-up study and commentary. Brit. med. $J ., 1,1138-1142$.

Joske, R. A., Finckh, E. S., and Wood, I. J. (1955). Gastric biopsy: a study of 1,000 consecutive successful gastric biopsies. Quart. J. Med., 24, 269-294.

Kay, A. W. (1953). Effect of large doses of histamine on gastric secretion of $\mathrm{HCl}$; an augmented histamine test. Brit. med. J. 2. 77-80. 